\title{
PARTIAL ABSENCE OF THE TRACHEA WITH LIVE BIRTH
}

\author{
BY \\ A. T. SANDISON \\ From the Department of Pathology, University and Royal Hospital for Sick Children, Glasgow
}

(RECEIVED FOR PUBLICATION JUNE 5, 1955)

Although anomalies of the trachea and oesophagus are not uncommon in paediatric practice, the case to be described is quite rare and no similar anomaly has been previously recorded at the Royal Hospital for Sick Children, Glasgow. Briefly, the condition is one of atresia of the larynx, partial absence of the trachea and a fistulous connexion between the oesophagus and the trachea. A point of considerable interest is that life was sustained for a short time and partial expansion of the lungs was achieved; but for the presence of much mucus in the lower respiratory passages life might have been prolonged further. A separate anomaly, namely extreme hypoplasia of one kidney, was also present.

The tracheal anomaly has already been recorded in the German literature by Fritz (1933) and similar but not identical cases have been described by Beneke (1905), Walcher (1928) and Kessel and Smith (1953). That described by Fritz is essentially similar to our case and occurred in a $43-\mathrm{cm}$. male infant who survived for about 12 minutes but failed to cry. Necropsy showed that a portion of the trachea $3 \mathrm{~cm}$. in length was entirely absent, that the larynx was fully formed but completely atretic distally and that a small fistula passed downwards connecting the oesophagus, from a point $3 \cdot 2 \mathrm{~cm}$. below the incisura interarytenoidea, with the upper extremity of the formed trachea. The lungs were poorly expanded.

Fritz discusses briefly the anomalies of the trachea and oesophagus, comprising (a) simple oesophageal atresia, (b) oesophageal atresia with the distal portion in continuity with the carina, $(c)$ tracheooesophageal fistula, $(d)$ atresia of the larynx, $(e)$ atresia of the larynx, partial absence of the trachea, the upper end of which is in continuity with the upper oesophagus while the lower part of the oesophagus takes origin at the carina, and $(f)$ atresia of the larynx, partial absence of the trachea and oesophago-tracheal fistula.

The present case and that described by Fritz belong to this last category. A similar but not identical case was described by Beneke (1905) in which the larynx was small and atretic, the trachea entirely absent, and the bifurcation of the major bronchi opened into the oesophagus.

Walcher (1928) also describes a neonatal absence of the trachea in a female infant of body length $45 \mathrm{~cm}$. and body weight $1,990 \mathrm{~g}$. who survived for four days. Here a $2.5 \mathrm{~cm}$. slit-like opening in the anterior wall of the oesophagus communicated with the tracheal bifurcation. No abnormality of the larynx other than atresia is described.

More recently Kessel and Smith (1953) describe a case of complete absence of the trachea with a fistulous connexion between the oesophagus and fused major bronchi. The larynx was normal but ended blindly below the level of the cricoid cartilage. The lungs were poorly expanded and histological sections showed large areas of atelectasis with extreme congestion, focal oedema and some alveolar haemorrhage. Kessel and Smith refer to no previous cases of complete or partial absence of the trachea but cite Wolman (1941) who gathered 10 cases of stenosis of the trachea and added one of his own, a female aged 2 months in whom the trachea tapered down from its laryngeal end to just above the bifurcation where the lumen measured only $1.5 \mathrm{~mm}$. The cartilaginous rings completely encircled the trachea. The lungs showed oedema, small alveolar haemorrhages and were rather collapsed.

\section{Case Report}

The infant (R.H.S.C. HR 257/54), a male, was delivered spontaneously by a healthy mother who is Rhesus positive and has a negative Wassermann reaction. At birth the child was very blue and did not cry. $\mathrm{He}$ moved actively, however, and the air passages were cleared by suction. Afterwards $1 \mathrm{ml}$. of lobeline was given and respiration improved. Intragastric oxygen was then administered and this improved the child's colour. His respiratory rate was then 8 per minute. On auscultation a loud, harsh systolic murmur was heard 
over the whole cardiac area. After 30 minutes intragastric oxygen was stopped and oxygen with $5 \%$ carbon dioxide given in an incubator. The respiratory rate was unchanged and the chest excursion poor. The heart beat was loud and forcible. A further $1 \mathrm{ml}$. of lobeline was given and the respiratory rate rose to 12 per minute. The child at no time cried, remained rather cold and its movement feeble. Fifteen minutes later the heart beat became faint and after a further 15 minutes the child died. He had survived for 4 hours and 42 minutes.

Necropsy showed a well-developed male infant of body weight $3,600 \mathrm{~g}$. The mouth and tongue were normal. The oesophagus was congested and a $2-\mathrm{mm}$. diameter circular pit was noticed in the anterior wall at about its midpoint. A probe passed through here entered the lower trachea through its convex dome. The larynx was unfused posteriorly and contained much mucus. The vocal cords appeared normal. The lower end of the larynx was atretic and the proximal trachea entirely absent (Fig. 1). The lower trachea, normally canalized, began with a closed, smoothly rounded, dome-like

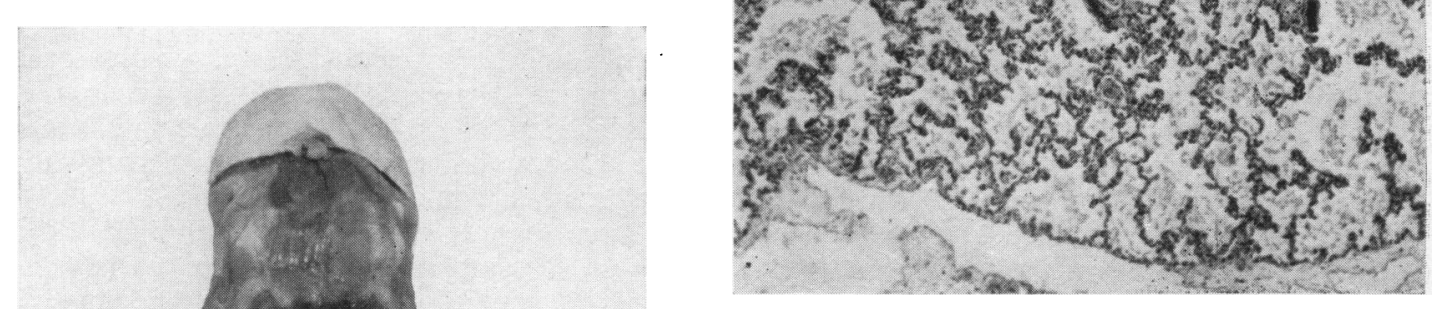

FIG. 2.-Section of lung showing some degree of expansion. Haemorrhages are present in many of the alveoli in this area. Haemalum and eosin $\times 60$.

convex extremity $2 \mathrm{~cm}$. above the carina at about the level of the oesophageal fistula and bifurcated normally. Much mucus was present in the distal trachea, causing obstruction. The lungs were rather poorly expanded. The gastro-intestinal tract was normal. The right kidney and ureter were extremely hypoplastic, but the left kidney, ureter, bladder, prostate and testes were normal. The right adrenal was considerably larger than the left. The thyroid and pituitary were normal; the thymus ( $12 \mathrm{~g}$. was rather large but of normal appearance.

Histology of the heart, thymus, salivary glands, pancreas, spleen, testes, left kidney, medulla oblongata and cerebral cortex showed no significant lesion.

The adrenals presented rather prominent foetal zones.

The right kidney showed very few glomeruli or tubules, but occasional cysts were present in fibrous tissue.

The liver showed haemopoietic activity.

The lungs were unevenly expanded with alternating areas of emphysema and atelectasis. Neither these nor the trachea showed any evidence of infection. The alveoli contained occasional squames and macrophages. The vessels were congested and small focal alveolar haemorrhages were noted (Fig. 2).

FIG. 1.-Macroscopic appearance of the air passages. The dome-like apex of the tracheal portion is seen with a probe passing into it from the oesophagus. The lungs are poorly expanded.

\section{Discussion}

That anomalies of the trachea and oesophagus 
should be common and of such considerable variety is more readily understood when the development of these structures is recalled. Frazer (1940) states that the pulmonary groove appears as a longitudinal sulcus in the floor of the foregut at the distal end of the primitive pharynx. The lower end grows backwards on the ventral side of the primitive oesophagus forming the rudimentary trachea. The trachea elongates after its separation from the oesophagus. This process of separation is not easily interpreted, but it appears that the long, slit-like opening into the oesophagus becomes shorter by the formation of an oesophago-tracheal septum made by fusion of lateral ridges from behind forwards. Little is added to this account by Hamilton, Boyd and Mossman (1945) or by Patten (1946). It can therefore be readily appreciated that anomalous development of the complex stages in this process may give rise to the various forms of tracheo-oesophageal abnormality mentioned briefly above.

In this instance it would appear that the upper portion of the pulmonary groove failed to form the tracheal tube, but that at the lower end the oesophago-tracheal septum formed normally. Both the lower trachea and the lower oesophagus therefore communicate with the proximal oesophagus. Life was sustained for some time in this child by oxygen passed through the oesophago-tracheal fistula and it would seem that the administration of intragastric oxygen would make this process easier. It is possible that life would have been longer sustained but for the accumulation of much mucus in the bronchi and distal trachea from which it could not escape.

It is interesting to recall the contention of Potter and Bohlender (1941), based partly on experimental findings and substantiated by two cases of respiratory anomaly, that the inflow and outflow of amniotic fluid is not essential for alveolar development. In one a mass of lung having no communication with the trachea developed alveoli and in the other the lung was also well developed despite tracheal obstruction by a malformed cricoid cartilage. In this case the lumen at this point was not more than $1 \mathrm{~mm}$. in diameter. Potter and Bohlender claim that in the latter case such a small opening could not permit any considerable inflow and outflow of amniotic fluid. They conclude that the alveoli in the foetus probably contain tiny amounts of transudate from the alveolar walls. The case of partial absence of the trachea just described would appear further to justify their thesis, although some small flow of amniotic fluid into the lungs must have occurred via the oesophagus as squames were found in the alveoli.

\section{Summary}

A case of a rare anomaly in the upper respiratory passage is described. Atresia of the larynx, partial absence of the trachea and oesophago-tracheal fistula were present. Nevertheless, the lungs were well formed and partially expanded. Life was sustained for a short time. An associated anomaly was extreme hypoplasia of one kidney.

I am indebted to Dr. J. P. O. Erskine, of the Overtoun Maternity Hospital, Dumbarton, for permission to quote from his clinical records, and to Mr. W. Mason, F.I.M.L.T., for technical assistance and for photographs.

\section{REFERENCES}

Beneke, R. (1905), Zbl. allg. Path. path. Anat., 16, 812. Frazer, J. E. (1940). A Manual of Embryology, 2nd ed. London. Fritz, E. (1933). Virchows Arch. path. Anat., 289, 264.

Hamilton, W. J., Boyd, J. D. and Mossman, H. W. (1945). Human Embryology. Cambridge.

Kessel, I. and Smith, J. N. (1953). Thorax, 8, 266.

Patten B. M. (1946). Human Embryology. New York.

Potter, E. L. and Bohlender, G. P. (1941). Amer. J. Obstet. Gynec., 42, 14.

Walcher, -. (1928). Dtsch. Z. ges. gerichtl. Med., 12, 292.

Wolman, I. J. (1941). Amer. J. Dis. Child., 61, 1263. 